\title{
An increase in neural tube defect notifications, South Australia, 2009-2010
}

\author{
Louise Flood, ${ }^{a}$ Wendy Scheil, ${ }^{a}$ Anh-Minh Nguyen, ${ }^{b}$ Leonie Sage ${ }^{a}$ and Joan Scott ${ }^{a}$ \\ Correspondence to Lovise Flood (e-mail: lovise.flood@health.sa.gov.au)
}

Introduction: In South Australia, reporting of live births, stillbirths of at least 20 weeks or $400 \mathrm{~g}$ birth weight, termination of pregnancies and congenital anomalies is mandated. We describe the investigation of an increase in notifications of neural tube defects (NTDs) in South Australia in 2009 and 2010 using data from several surveillance systems.

Methods: NTD trend data from 1966 to 2010 were reviewed. Comparisons of pregnancies affected by an NTD in 2009 and 2010 were made with pregnancies affected by an NTD in the period 2003-2008 and with all pregnancies in 2009 and 2010. Statistical analysis was undertaken using Poisson regression, chi-squared or Fisher's exact tests.

Results: The prevalence of NTD-affected pregnancies was 1.95 per 1000 births (39 cases) in 2010 and 1.91 per 1000 births in 2009 (38 cases), the highest annual rates since 1991. Case series comparisons indicated women with NTDaffected pregnancies in 2009 and 2010 were less likely to be Caucasian compared with women who had NTD-affected pregnancies in the period 2003-2008. Women born in the Middle East and African region $(n=7)$ were significantly more likely to have NTD-affected pregnancies in the years 2009 and 2010 (relative risk: 3.03; 95\% confidence interval: 1.39-6.62) compared with women born in the Oceania region.

Discussion: The increased notifications of NTDs can only be partially explained by the increase in numbers of women from the Middle East and African region, with no other contributory causes revealed. This analysis highlighted areas where prevention efforts should be strengthened and surveillance data improved.

$\mathrm{T}$ he neural tube usually closes by day 28 of prenatal life, and incomplete or incorrect closure results in malformations called neural tube defects (NTDs). ${ }^{1,2}$ There is a spectrum of severity of NTDs from anencephaly, which is incompatible with life beyond the neonatal period, to spina bifida occulta, which may be asymptomatic. ${ }^{1}$

Globally there are wide variations in birth prevalence of NTDs related to geography, ${ }^{3,4}$ race and ethnicity $^{2,3}$ and socioeconomic status. ${ }^{3,5-9}$ The majority of NTDs are non-syndromal with various maternal risk factors associated with increased likelihood of development of NTDs in offspring including: folate deficiency in the periconceptional period, ${ }^{10,11}$ low maternal vitamin $\mathrm{B} 12,{ }^{10,12,13}$ a previous NTD-affected pregnancy, ${ }^{3,4,14}$ diabetes mellitus, ${ }^{11}$ drug exposure during pregnancy, ${ }^{14-16}$ overweight and obesity, ${ }^{3,17-19}$ genetic alterations in folate-related genes, ${ }^{2-4}$ exposure to environmental pollutants 20,21 and early pregnancy maternal hyperthermia. ${ }^{3,11,20,22}$
Periconceptional folic acid supplementation has been shown to decrease the risk of NTDs. ${ }^{23,24}$ Folic acid supplementation one month prior and three months post conception is recommended to reduce the risk of an NTD-affected pregnancy. ${ }^{4,25-27}$ In Australia, voluntary fortification of selected foods with folic acid was permitted from 1995, with fortification of non-organic, bread-making flour mandated from September 2009. ${ }^{7}$

In South Australia, reporting of all births, induced termination of pregnancy (ITOP) procedures and congenital abnormalities to the Pregnancy Outcome Unit (POU) of the South Australian Department for Health and Ageing is mandated, ${ }^{28}$ and form the Birth Defects Register surveillance system.

An increase in the number of notifications of NTDs was observed in South Australia in 2009 and $2010,{ }^{28,29}$ with 39 and 38 NTD-affected pregnancies reported, respectively, as compared with between 21 and 25 notifications annually in the period 2003 to 2008 .

\footnotetext{
a Pregnancy Outcome Unit, Epidemiology Branch, South Australian Department for Health and Ageing, Adelaide, South Australia.

Health Statistics Unit, Epidemiology Branch, South Australian Department for Health and Ageing, Adelaide, South Australia.

Submitted: 9 October 2012; Published: 30 June 2013

doi: 10.5365/wpsar.2012.3.3.006
} 
To help determine whether this increase represented a true increase, data from 1966 were reviewed. To discover possible underlying reasons for this increase and identify intervention targets, an investigation was undertaken comparing NTD-affected pregnancy notifications in 2009 and 2010 with notifications in the period 2003-2008 and with all pregnancy outcomes in the years 2009 and 2010 .

\section{METHODS}

\section{Data sources}

NTD trend data from 1966 to 2010 were accessed from the Birth Defects Register surveillance database. Information on NTD-affected pregnancies (excluding spina bifida occulta) was obtained from three sources:

- The Abortion Statistics Collection is based on the Doctors Certificate and Notice Schedule (ITOP procedure form). Notifiers must include "grounds for termination of pregnancy," with "suspected medical condition of fetus" specified.

- The Perinatal Statistics Collection, using the Supplementary Birth Record completed by hospital and home-birth midwives, records the outcome of all live births, stillbirths of at least 20 weeks duration or $400 \mathrm{~g}$ birth weight and includes a question regarding congenital abnormalities apparent in the baby.

- The Birth Defects Register includes reports of an NTD within first year of life from the Congenital Abnormality Form, which is completed by the notifying medical officer, midwife or South Australian Birth Defects Register staff.

Although reporting of births, ITOP procedures and congenital abnormalities is legally required, information is not always complete. To ensure the accuracy and maximize the completeness of the database of NTD notifications for the period 2003-2010, the data items were verified against the following:

1. the Open Architecture Clinical Information System, which contains electronic records of hospital discharge summaries, laboratory investigations and radiology undertaken in the public system;

2. the Integrated South Australian Activity Collection, a database of all hospitalizations in South Australia, to determine indigenous status and country of birth;

3. maternal and/or child case notes; and

4. treating doctor of the woman.

The POU is not permitted to contact the mother.

\section{Analyses}

To determine whether there was a systematic difference in the characteristics of women with NTD notifications in the years 2009 and 2010, the following comparisons were undertaken:

1. a case series comparison of NTD notifications from 2009 and 2010 with those from the period 2003-2008; and

2. a cohort comparison of NTD notifications in 2009 and 2010 with all South Australian pregnancy outcomes (excluding NTD cases) in 2009 and 2010.

Comparisons included demographics (age, race, country of birth, location of residence), previous pregnancies (parity, gravidity and number of previous terminations, live births and stillbirths), medical history (assisted reproductive therapies [ART], diabetes mellitus and epilepsy), smoking status and body mass index (BMI). Country of birth was grouped using the Standard Australian Classification of Countries. ${ }^{30}$ Data on folate use were only available for women with NTD-affected pregnancies; therefore, comparisons were limited to the case series. The relative risk for women in regard to BMI was not calculated due to the considerable number of cases where these data could not be ascertained.

As South Australia experienced an extreme heat wave in early $2009,{ }^{31}$ meteorological effects were also analysed for the case series comparison. Maximum daily ambient temperature for 14 weather stations across South Australia was accessed from the Australian Government Bureau of Meteorology web site. ${ }^{32}$ 
Each woman with an NTD-affected pregnancy was assigned to the nearest weather station; women from metropolitan Adelaide were assigned to Kent Town weather station (in central Adelaide). The estimated date of conception was calculated from the date of the last menstrual period, if known, or from the estimated date of confinement. The number of days with a recorded maximum temperature of $35{ }^{\circ} \mathrm{C}$ or more from the date of conception until day 28 was calculated and compared for women with NTD-affected pregnancies in the periods 2009-2010 and 2003-2008.

Statistical analysis was undertaken using STATA 12. The level of significance was set at 5\%. NTD prevalence trend was analysed with Poisson regression. Other analyses were undertaken using chi-squared tests with Fisher's exact test used where expected counts were less than five. Missing data were excluded from analyses.

Ethical approval was granted by the South Australian Health Ethics Committee and the Aboriginal Health Council of South Australia.

\section{RESULTS}

\section{Prevalence of NTDs}

The prevalence of NTDs was relatively stable between 1966 and 1990 and declined significantly thereafter (Poisson regression 1966 to 2010, $P<0.001$ ). Secular trend data from 1990 incorporating the number of notifications in 2009 and 2010 continued to trend downward but at a reduced rate (from 2.8\% decline during the period $1990-2008$ to $1.8 \%$ decline between 1990 and 2010). The annual rate of NTD-affected pregnancies per 1000 births was 1.91 in 2009 and 1.95 in 2010, which were the highest rates since 1991 (2.03 per 1000 births). The birth prevalence (births and ITOP procedures) of anencephaly, spina bifida, encephalocoele and all NTDs show considerable yearly variation. Spina bifida and anencephaly are the most common types of NTDs (Figure 1).

NTD-affected pregnancies in 2009 and 2010 compared with NTD-affected pregnancies in 2003-2008

Women with NTD-affected pregnancies in 2009 and 2010 as compared with women with NTD-affected pregnancies in the period 2003-2008 were similar in regard to age, marital status, plurality, gravidity and Indigenous status. The majority of women were Caucasian; however, there were significantly fewer Caucasian women with NTD-affected pregnancies in 2009 and 2010 compared with the period 2003-2008 $(P=0.01)$. Region of birth was significantly different between cases in the two time periods $(P=0.01)$. Regional analysis indicated that women with NTDaffected pregnancies in 2009 and 2010 were more likely to have been born in the Middle East and African region $(P=0.04)$. Analysis by presence of epilepsy or diabetes mellitus was unremarkable. Analysis by ART use and BMI was hampered by a considerable number of cases where these data could not be ascertained (Table 1).

Thirty-six women (46.8\%) with NTD-affected pregnancies in 2009 and 2010 did not experience any hot days with maximum reported ambient temperature of $35{ }^{\circ} \mathrm{C}$ or above in early pregnancy compared with $70(51.5 \%)$ women with NTD-affected pregnancies in 2003-2008. There was no significant difference in the number of hot days (no hot days compared with at least one hot day) in early pregnancy for women with NTDaffected pregnancies in 2009 and 2010 as compared with the period 2003-2008.

Fewer women with NTD-affected pregnancies in the 2009-2010 period were reported as having taken no folate compared with the 2003-2008 period (six [7.8\%] compared with 19 [14.0\%]); however data regarding folate use were not available for 18 (23.4\%) and $51(37.5 \%)$ women, respectively (Table 2 ).

NTD-affected pregnancies in 2009 and 2010 compared with all pregnancies in 2009 and 2010

Women with NTD-affected pregnancies were significantly more likely to be born in the Middle East and African region (relative risk [RR]: 3.03; 95\% confidence interval [CI]: 1.39-6.62) compared with all pregnancies in 2009 and 2010 (excluding NTD births). Among the seven Asian-born women with NTD-affected pregnancies, four came from India (57\%). Women with NTD-affected pregnancies in 2009 and 2010 were also more likely to report using ART than women with births in 2009 and 2010 (RR 4.89, 95\% Cl: 1.97-12.14, $P=0.0002$ ) (Table 3).

Women with NTD-affected pregnancies in 2009 and 2010 were less likely to be married or in a de facto 
Table 1. Characteristics of women with neural tube defect-affected pregnancies (births and termination procedures), South Australia, 2003-2008 and 2009-2010

\begin{tabular}{|c|c|c|c|c|c|}
\hline \multirow{2}{*}{ Characteristics } & \multicolumn{2}{|c|}{ 2003-2008 } & \multicolumn{2}{|c|}{ 2009-2010 } & \multirow{2}{*}{$p$-value } \\
\hline & $n$ & $\%$ & $n$ & $\%$ & \\
\hline \multicolumn{6}{|l|}{ Age } \\
\hline$<30$ years & 64 & 47.1 & 38 & 49.4 & \multirow{2}{*}{$P=0.75$} \\
\hline$\geq 30$ years & 72 & 52.9 & 39 & 50.6 & \\
\hline \multicolumn{6}{|l|}{ Marital status } \\
\hline Married/de facto & 114 & 83.8 & 62 & 80.5 & \multirow{3}{*}{$P=0.39$} \\
\hline Other & 20 & 14.7 & 15 & 19.5 & \\
\hline Unknown & 2 & 1.5 & 0 & 0.0 & \\
\hline \multicolumn{6}{|l|}{ Plurality } \\
\hline Singleton & 131 & 96.3 & 76 & 98.7 & \multirow{2}{*}{$P=0.66$} \\
\hline Multiple & 4 & 2.9 & 1 & 1.3 & \\
\hline \multicolumn{6}{|l|}{ Race } \\
\hline Caucasian & 121 & 89.0 & 61 & 79.2 & \multirow{3}{*}{$P=0.01$} \\
\hline Not Caucasian & 11 & 8.1 & 16 & 20.8 & \\
\hline Unknown & 4 & 2.9 & 0 & 0.0 & \\
\hline \multicolumn{6}{|l|}{ Region of birth } \\
\hline Oceania & 114 & 83.8 & 60 & 77.9 & \multirow{5}{*}{$P=0.01$} \\
\hline Europe, Americas and former USSR & 11 & 8.1 & 1 & 1.3 & \\
\hline Middle East and Africa & 3 & 2.2 & 7 & 9.1 & \\
\hline Asia & 7 & 5.1 & 7 & 9.1 & \\
\hline Unknown & 1 & 0.7 & 2 & 2.6 & \\
\hline \multicolumn{6}{|l|}{ Indigenous status } \\
\hline Aboriginal and/or Torres Strait Islander & 2 & 1.5 & 3 & 3.9 & \multirow{3}{*}{$P=0.36$} \\
\hline Not Aboriginal or Torres Strait Islander & 131 & 96.3 & 74 & 96.1 & \\
\hline Unknown & 3 & 2.2 & 0 & 0.0 & \\
\hline \multicolumn{6}{|l|}{ Gravidity } \\
\hline Primigravida & 41 & 30.1 & 26 & 33.8 & \multirow{2}{*}{$P=0.59$} \\
\hline Multigravida & 95 & 69.9 & 51 & 66.2 & \\
\hline \multicolumn{6}{|l|}{ Parity } \\
\hline Primipara & 60 & 44.1 & 36 & 46.8 & \multirow{2}{*}{$P=0.71$} \\
\hline Multipara & 76 & 55.9 & 41 & 53.2 & \\
\hline \multicolumn{6}{|l|}{ Assisted reproductive therapy use } \\
\hline Yes & 10 & 7.4 & 5 & 6.5 & \multirow{3}{*}{$\mathrm{N} / \mathrm{A}^{\dagger}$} \\
\hline No & 84 & 61.8 & 61 & 79.2 & \\
\hline Unknown & 42 & 30.9 & 11 & 14.3 & \\
\hline \multicolumn{6}{|l|}{ Body mass index } \\
\hline Underweight or normal weight $\left(<25 \mathrm{~kg} / \mathrm{m}^{2}\right)$ & 14 & 10.3 & 14 & 18.2 & \multirow{3}{*}{$\mathrm{N} / \mathrm{A}^{\dagger}$} \\
\hline Overweight or obese $\left(\geq 25 \mathrm{~kg} / \mathrm{m}^{2}\right)$ & 19 & 14.0 & 30 & 39.0 & \\
\hline Unknown & 103 & 75.7 & 33 & 42.9 & \\
\hline \multicolumn{6}{|l|}{ Residence* } \\
\hline Metropolitan & 100 & 75.8 & 52 & 71.2 & -018 \\
\hline Not metropolitan & 32 & 24.2 & 21 & 28.8 & -0.40 \\
\hline
\end{tabular}

Note: Pearson chi-squared test, or Fisher's exact test where expected frequencies are small.

USSR - Union of Soviet Socialist Republics; N/A - not applicable.

* Cases in interstate residents $(n=8)$ not shown.

$\dagger \quad$ Calculation not undertaken due to large numbers of unknowns. 
Figure 1. Birth prevalence (births and termination procedures) of neural tube defects, spina bifida, anencephaly and encephalocele, South Australia, 1966 to 2010

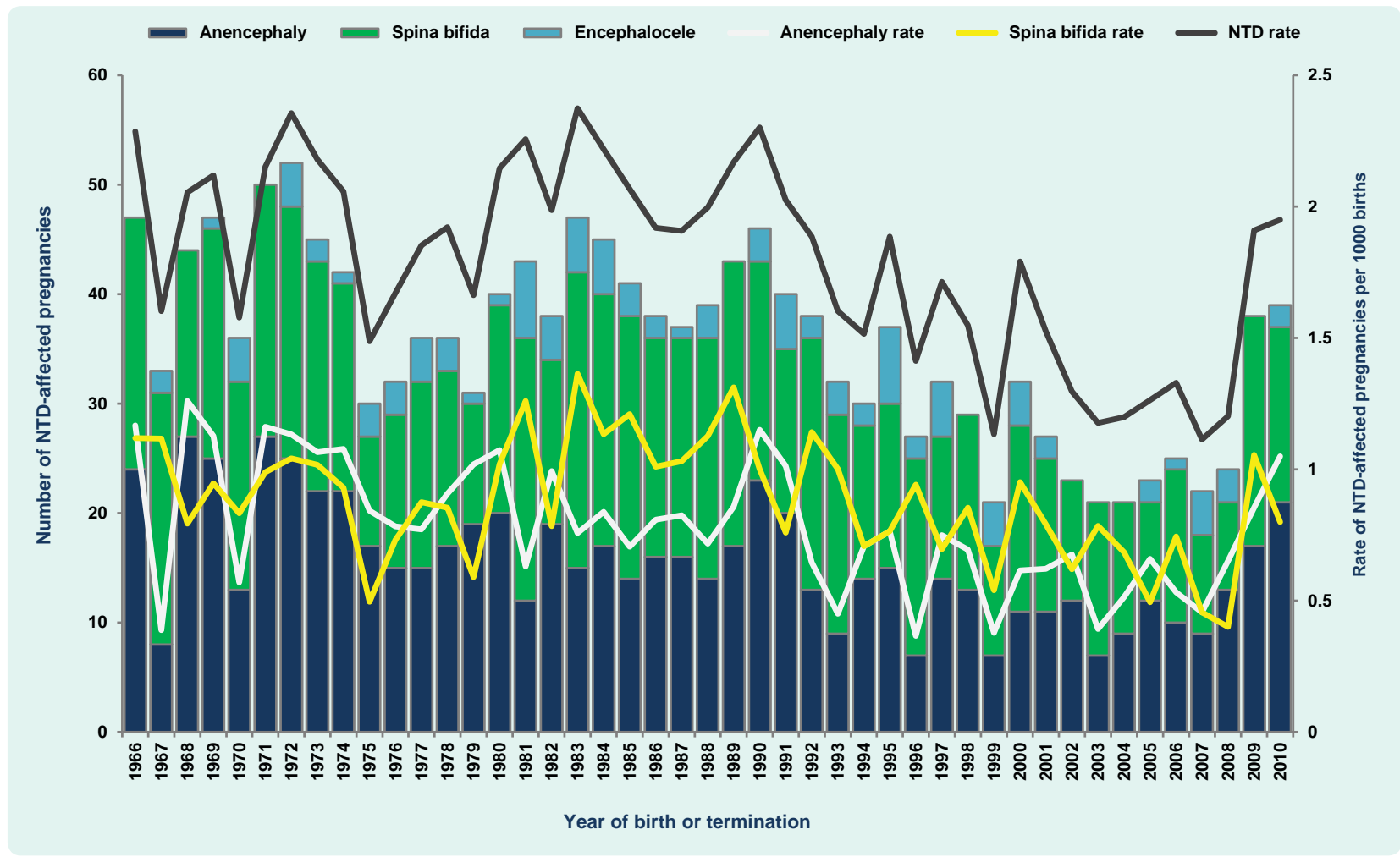

NTD - neural tube defect

Note: The South Australian folate promotion campaign ran from October 1994 to August 1995.

Table 2. Folate consumption of women with neural tube defect-affected pregnancies (births and termination procedures), South Australia, 2003-2008 and 2009-2010

\begin{tabular}{|c|c|c|c|c|c|c|c|}
\hline \multirow{2}{*}{\multicolumn{2}{|c|}{ Folate consumption }} & \multicolumn{4}{|c|}{ Year of delivery or termination } & \multirow{2}{*}{\multicolumn{2}{|c|}{ Total }} \\
\hline & & \multicolumn{2}{|c|}{2003 to 2008} & \multicolumn{2}{|c|}{2009 to 2010} & & \\
\hline & & $n$ & $\%$ & $n$ & $\%$ & \multirow{2}{*}{$\begin{array}{l}n \\
56\end{array}$} & \multirow{2}{*}{$\begin{array}{c}\% \\
26.3\end{array}$} \\
\hline \multirow{3}{*}{$\begin{array}{l}\text { Periconceptional } \\
\text { folate }\end{array}$} & Before and early pregnancy & 35 & 25.7 & 21 & 27.3 & & \\
\hline & Early pregnancy only & 16 & 11.8 & 11 & 14.3 & 27 & 12.7 \\
\hline & Unknown timing & 15 & 11.0 & 21 & 27.3 & 36 & 16.9 \\
\hline \multicolumn{2}{|l|}{ No folate } & 19 & 14.0 & 6 & 7.8 & 25 & 11.7 \\
\hline \multicolumn{2}{|l|}{ Unknown folate } & 51 & 37.5 & 18 & 23.4 & 69 & 32.4 \\
\hline \multicolumn{2}{|l|}{ Total } & 136 & 100.0 & 77 & 100.0 & 213 & 100.0 \\
\hline
\end{tabular}

relationship compared with other women giving birth in these years (21\% compared with 60\%). Otherwise, women with NTD-affected pregnancies were similar to women with births in 2009 and 2010 in regard to age, plurality, Indigenous status, Caucasian ethnicity, gravidity, parity and metropolitan residence (Table 3). Analysis by presence of epilepsy or diabetes mellitus was unremarkable.

\section{DISCUSSION}

This study aimed to investigate an observed increase in the number of NTD-affected pregnancies notified in 2009 and 2010 in South Australia using routinely collected surveillance data. No explanation was found that could fully account for the increase in NTD notifications; however, factors that were likely contributory were 
Table 3. Characteristics of women with neural tube defect-affected pregnancies (births and termination procedures) and all births, South Australia, 2009 and 2010

\begin{tabular}{|c|c|c|c|c|c|c|c|}
\hline \multirow{2}{*}{ Characteristics } & \multicolumn{2}{|c|}{ NTD } & \multicolumn{2}{|c|}{ Births $^{\ddagger}$} & \multirow{2}{*}{$\begin{array}{c}\text { Risk per } \\
1000\end{array}$} & \multirow{2}{*}{\multicolumn{2}{|c|}{ Relative risk $^{\S}(95 \% \mathrm{Cl})$}} \\
\hline & $\mathbf{n}$ & $\%$ & $n$ & $\%$ & & & \\
\hline \multicolumn{8}{|l|}{ Age } \\
\hline$<30$ years & 38 & 49.4 & 19302 & 48.4 & 1.97 & \multirow{2}{*}{1.04} & \multirow{2}{*}{$(0.66-1.62)$} \\
\hline$\geq 30$ years & 39 & 50.6 & 20567 & 51.6 & 1.90 & & \\
\hline \multicolumn{8}{|l|}{ Marital status } \\
\hline Married/de facto & 62 & 80.5 & 35448 & 88.9 & 1.75 & \multirow{3}{*}{0.52} & \multirow{3}{*}{$(0.29-0.91)$} \\
\hline Other & 15 & 19.5 & 4420 & 11.1 & 3.39 & & \\
\hline Unknown & 0 & 0.0 & 1 & 0.0 & & & \\
\hline \multicolumn{8}{|l|}{ Plurality } \\
\hline Singleton & 76 & 98.7 & 38617 & 96.9 & 1.97 & \multirow{2}{*}{2.46} & \multirow{2}{*}{$(0.34-17.68)$} \\
\hline Multiple & 1 & 1.3 & 1252 & 3.1 & 0.80 & & \\
\hline \multicolumn{8}{|l|}{ Race } \\
\hline Caucasian & 61 & 79.2 & 33451 & 83.9 & 1.82 & \multirow{2}{*}{0.73} & \multirow{2}{*}{$(0.42-1.27)$} \\
\hline Not Caucasian & 16 & 20.8 & 6418 & 16.1 & 2.49 & & \\
\hline \multicolumn{8}{|l|}{ Region of birth } \\
\hline Oceania & 60 & 77.9 & 32471 & 81.4 & 1.85 & 1.00 & \\
\hline Asia & 7 & 9.1 & 3795 & 9.5 & 1.84 & 1.00 & $(0.46-2.18)$ \\
\hline Middle East and Africa & 7 & 9.1 & 1245 & 3.1 & 5.60 & 3.03 & $(1.39-6.62)$ \\
\hline Other & 2 & 2.6 & 1 & 0.0 & & & \\
\hline Unknown & 1 & 1.3 & 2357 & 5.9 & & & \\
\hline \multicolumn{8}{|l|}{ Indigenous status } \\
\hline Aboriginal and/or Torres Strait Islander & 3 & 3.9 & 1245 & 3.1 & 2.41 & \multirow{2}{*}{1.26} & \multirow{2}{*}{$(0.40-3.98)$} \\
\hline Not Aboriginal or Torres Strait Islander & 74 & 96.1 & 38624 & 96.9 & 1.92 & & \\
\hline \multicolumn{8}{|l|}{ Gravidity } \\
\hline Primigravida & 26 & 33.8 & 12153 & 30.5 & 2.14 & \multirow{2}{*}{1.16} & \multirow{2}{*}{$(0.73-1.86)$} \\
\hline Multigravida & 51 & 66.2 & 27716 & 69.5 & 1.84 & & \\
\hline \multicolumn{8}{|l|}{ Parity } \\
\hline Primipara & 36 & 46.8 & 16781 & 42.1 & 2.15 & 121 & 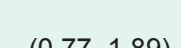 \\
\hline Multipara & 41 & 53.2 & 23088 & 57.9 & 1.78 & 1.21 & (0.11-1.05) \\
\hline Assisted reproductive therapy use & & & & & & & \\
\hline Yes & 5 & 6.5 & 653 & 1.6 & 7.66 & 4.89 & $(1.97-12.14)$ \\
\hline No & 61 & 79.2 & 39216 & 98.4 & 1.56 & & \\
\hline Unknown & 11 & 14.3 & 0 & 0.0 & & & \\
\hline Body mass index & & & & & & & \\
\hline Underweight/normal $(<25 \mathrm{~kg} / \mathrm{m} 2)$ & 14 & 18.2 & 14838 & 37.2 & & & Nat \\
\hline Overweight or obese $(\geq 25 \mathrm{~kg} / \mathrm{m} 2)$ & 30 & 39.0 & 15373 & 38.6 & & & $N / A^{\prime}$ \\
\hline Unknown & 33 & 42.9 & 9658 & 24.2 & & & $\mathrm{~N} / \mathrm{A}^{\dagger}$ \\
\hline Residence* $^{*}$ & & & & & & & \\
\hline Metropolitan & 52 & 71.2 & 29657 & 74.9 & 1.75 & & $(050-138)$ \\
\hline Not metropolitan & 21 & 28.8 & 9959 & 25.1 & 2.10 & 0.83 & $(0.50-1.38)$ \\
\hline
\end{tabular}

NTD - neural tube defect; $\mathrm{Cl}$ - confidence interval; N/A - not applicable

Excludes interstate residents ( $n=4$ cases; $n=253$ comparison births)

Calculations not undertaken due to large number of missing data

Excludes 34 NTD notifications from 2009 to 2010

Unknowns excluded for calculation of relative risk 
found. Women with NTD-affected pregnancies in 2009 and 2010 were less likely to be Caucasian as compared with women with NTD-affected pregnancies in the period 2003-2008. Women born in the Middle East and African region were more likely than women born in the Oceania region to have NTD-affected pregnancies in 2009 and 2010.

An elevated number of notifications can be due to a change in detection methods, a change in notification practices or a real increase in disease. Given the severe nature of most NTDs, the majority will be diagnosed either prenatally or within the first year of life; ${ }^{1}$ therefore, it is unlikely that a change in detection methods could account for the increase in NTD notifications. Since 1998, the South Australian Births Defects Register has been screening childhood admission data for missing notifications; hence, it is unlikely that a change in notification practices could account for the increase in notifications. It is likely that the increase in NTD notifications reflected a real increase in the number of NTD-affected pregnancies and warranted further investigation.

Women with NTD-affected pregnancies in 2009 and 2010 in this study were less likely to be Caucasian and more likely to have been born in the Middle East and African region compared with women who had NTD-affected pregnancies in the period 2003-2008. Women born in the Middle East and African region were also significantly more likely to have NTD-affected pregnancies in the years 2009-2010 compared with women born in the Oceania region. Periconceptional folic acid is a key modifiable risk factor in NTD prevention, and several studies have noted reduced intake of folic acid supplementation in pregnant ethnic minority women compared with women of the ethnic majority. ${ }^{33,34}$ Poor language proficiency is also likely a barrier to adequate folic acid supplementation. ${ }^{34}$ Closer inspection of folate use among the Middle East and African-born women and Asian-born women with NTD-affected pregnancies in 2009 and 2010 did not reveal a consistent pattern of reduced folate consumption during pregnancy.

Of the women with NTD-affected pregnancies in 2009 and $2010,69 \%$ reported taking folate (8\% reported not taking folate during pregnancy; $23 \%$ had missing data). Recent data from the South Australian Monitoring and Surveillance System indicated that in 2010,
92.6\% (95\% Cl: 88.4\%-95.6\%) of women currently pregnant or pregnant within the past three years reported taking folic acid supplementation in pregnancy. ${ }^{35}$ Although these proportions are not directly comparable, there is evidence of the continued need for education of women regarding the importance of periconceptional folic acid.

Three women had two NTD-affected pregnancies within the 2003-2010 period. Women who have had one NTD-affected pregnancy have a $2 \%-3 \%$ chance of a subsequent NTD-affected pregnancy. ${ }^{14}$ It would be expected that women who are multiparous would more likely be exposed to health promotion messages regarding folate during previous pregnancies and thus have a greater awareness of the need for periconceptional folic acid. ${ }^{34}$ However, in our study, there was no significant difference between gravidity or parity and risk of an NTD-affected pregnancy. This is in keeping with a previously reported link between inadequate folate consumption and multiparity. ${ }^{33}$ It is important that women of childbearing age at increased risk of NTD such as women with a previous NTD-affected pregnancy or family history of NTD are advised to take $5 \mathrm{mg}$ of folic acid supplementation daily orally as opposed to the 0.5 mg recommended for women not at increased risk. ${ }^{25-}$ 27 This may represent opportunities missed by health services to inform pregnant women of the importance of periconceptional folic acid use in future pregnancies.

Inadequate vitamin B12 may also be associated with an increased risk of NTD. ${ }^{10,12,13,36}$ Vitamin B12 deficiency is likely to be a public health issue in both developed and developing countries worldwide; however, there is a lack of population-based prevalence studies. ${ }^{37}$ In a South Australian-based study of recently arrived refugees, no women of childbearing age (15-44 years) from Middle Eastern and Southern and central Asian countries were folate deficient (serum folate $<7 \mathrm{nmol} / \mathrm{L}$ ), although approximately $26.1 \%$ were vitamin B12 deficient (serum vitamin B12 < 150 pmol/L) (Dr Jillian Benson, Senior Medical Officer, Migrant Health Service, Adelaide, personal communication, 24 July 2012). There have been no trials of vitamin B12 supplementation in pregnancy; hence, it is currently unknown whether vitamin B12 supplementation is of benefit in NTD prevention. ${ }^{36}$ It may be that vitamin B12 supplementation in addition to folic acid supplementation is required to minimize the risk of NTD in this community. 
Married or de facto married women were significantly less likely to have had NTD-affected pregnancies in 2009-2010 compared with other women giving birth. However, this observation is more likely to reflect the characteristics of the Abortion Statistics Collection data set rather than risk factors for NTD. Case series comparison indicated the cases in the periods 20032008 and 2009-2010 were similar with respect to marital status.

More women with NTD-affected pregnancies in 2009 and 2010 reported using ART than all other women with births in 2009 and 2010. However, there is likely differential misclassification of exposure due to incomplete ascertainment of ART usage in birth data compared with NTD notifications because of measurement bias, especially recall bias. In the South Australia 2009 to 2010 birth data, ART was reported in $1.6 \%$ births, whereas the Australian Institute of Health and Welfare estimated that $4.0 \%$ of births had used ART in Australia. ${ }^{38,39}$ Therefore, it is likely that there has been incomplete ascertainment of pregnancies where ART has occurred in the 2009 to 2010 birth data. Moreover, women who undergo ART may be different in other ways that affect NTD risk apart from the requirement for ART. A recent study using South Australian data found no significant difference in risk of neurological congenial anomalies in pregnancies resulting from ART compared with all pregnancies. ${ }^{40}$

Maternal hyperthermia in early pregnancy is associated with an increased risk of an NTD-affected pregnancy. $3,11,20,22$ South Australia experienced an extreme heat wave in early 2009, ${ }^{31}$ therefore, meteorological effects were analysed as a possible reason for increased numbers of women with NTD-affected pregnancies in 2009 and 2010. However, no significant difference was found. Improving methodologies to determine the association of meteorological effects on congenital anomalies is important as Australia is likely to experience more extreme weather conditions, including heat waves, in association with climate change. ${ }^{31}$

This study, as it was based on surveillance and other routinely collected data, has several limitations. Data were obtained from three separate sources, each with a different focus and thus different variables. Missing data was also an issue, particularly for BMI, ART and folate status, making interpretation of these comparisons difficult. Folate consumption was only routinely collected for women with NTD-affected pregnancies with data frequently missing. Clinicians reported they were reluctant to question women with NTD-affected pregnancies, particularly those requesting ITOP, regarding their periconceptional folate intake given the sensitivity of the situation. As POU is not legally permitted to contact the women, this analysis had to rely on reported data.

Additionally, measurement bias was likely as notifications of pregnancies with no reported complications are subject to less scrutiny than pregnancies with reported congenital anomalies. Women with NTD-affected pregnancies, compared to women without complications, may be more likely to recall medical procedures (e.g. ART). Exclusion of women with previous NTDs from the analyses did not result in any significant difference from the results reported. As this study was based on an observed population, it involved small numbers, and therefore, multivariable analysis to control for potential confounders was not feasible.

This study has several strengths. It reported a wholeof-state collection of pregnancies with a NTD including both ITOP procedures and births. There was likely almost complete capture of NTD-affected pregnancies (excluding early miscarriages) due to mandatory reporting and routine screening for missed notifications. Inclusion of ITOP in analysis of NTD epidemiology is essential as in South Australia 84\% of pregnancies with an NTD during the period 2003-2010 resulted in ITOP. This study was based on routinely collected data which enabled comparison of NTD-affected pregnancies in 2009 and 2010 with all births in 2009 and 2010 and NTD-affected pregnancies in the period 2003-2008 for a large number of demographic factors and risk factors. Additionally, trend data on NTD birth prevalence were available for more than 40 years.

In conclusion, a small but significant increase in the numbers of women born in the Middle East and African region partially contributed to the observed increase in notifications of NTD-affected pregnancies in South Australia in 2009 and 2010. However, this cannot fully explain the observed increase in NTD notifications, and it is likely that these two years of increased notifications represent a chance event rather than signalling the beginning of an epidemiological shift. This study highlighted the need for surveillance systems of congenital anomalies to be able to respond 
to such increases. It also drew attention to the need to improve universal health promotion messages regarding periconceptional folic acid supplementation in pregnancy and to further investigate other potentially contributory nutritional deficiencies such as vitamin B12, particularly among women born in the Middle East and Africa.

\section{Conflicts of interest}

None declared.

\section{Funding}

None.

\section{Acknowledgements}

We thank the current and previous staff of the Pregnancy Outcome Unit and South Australia Birth Defects Register for data collection and collation, as well as those who notified to the Registers. We also acknowledge Graeme Tucker and Britt Catcheside of the Health Statistics Unit, Epidemiology Branch, South Australia Health for assistance with data analysis.

\section{References:}

1. Abeywardana S, Sullivan EA. Neural tube defects in Australia: an epidemiological report. Cat. No. PER 45. Sydney, National Perinatal Statistics Unit Australian Institute of Health and Welfare, 2008 (http://www.aihw.gov.au/WorkArea/DownloadAsset. aspx?id=6442458964, 7 July 2012).

2. Green NS. Folic acid supplementation and prevention of birth defects. The Journal of Nutrition, 2002, 132 Suppl;2356S2360S. pmid: 12163692

3. Frey L, Hauser WA. Epidemiology of neural tube defects. Epilepsia, 2003, 44 Suppl 3;4-13. doi:10.1046/j.1528-1157.44.s3.2.x pmid: 12790881

4. Heseker HB et al. Not all cases of neural-tube defect can be prevented by increasing the intake of folic acid. The British Journal of Nutrition, 2009, 102:173-180. doi:10.1017/ S0007114508149200 pmid:19079944

5. Macdonell JE, Campbell H, Stone DH. Lead levels in domestic water supplies and neural tube defects in Glasgow. Archives of Disease in Childhood, 2000, 82:50-53. http://dx.doi. org/10.1136/adc.82.1.50 pmid:10630913

6. McGuire $\mathrm{M}$ et al. Prevalence and predictors of periconceptional folic acid uptake-prospective cohort study in an Irish urban obstetric population. Human Reproduction (Oxford, England), 2010, 25:535-543. doi:10.1093/humrep/dep398 pmid:19910320

7. Abeywardana $\mathrm{S}$ et al. Prevalence of neural tube defects in Australia prior to mandatory fortification of bread-making flour with folic acid. Australian and New Zealand Journal of Public Health, 2010, 34:351-355. doi:10.1111/j.1753-6405.2010.00565.x pmid:20649773
8. Smithells RW, Sheppard S, Schorah CJ. Vitamin deficiencies and neural tube defects. Archives of Disease in Childhood, 1976, 51:944-950. doi :10.1136/adc.51.12.944 pmid: 1015847

9. Li Z et al. A population-based case-control study of risk factors for neural tube defects in four high-prevalence areas of Shanxi province, China. Paediatric and Perinatal Epidemiology, 2006, 20:43-53. doi:10.1111/j.1365-3016.2006.00694.x pmid: 16420340

10. Zhang T et al. Maternal serum vitamin B12, folate and homocysteine and the risk of neural tube defects in the offspring in a high-risk area of China. Public Health Nutrition, 2009, 12:680-686. doi:10.1017/S1368980008002735 pmid:18547453

11. Mitchell LE et al. Spina bifida. Lancet, 2004, 364:1885-1895. doi :10.1016/S0140-6736(04)17445-X pmid:15555669

12. Ray JG, Blom HJ. Vitamin B12 insufficiency and the risk of fetal neural tube defects. QJM, 2003, 96:289-295. doi:10.1093/ qjmed/hcg043 pmid: 12651973

13. Molloy AM et al. Maternal vitamin B12 status and risk of neural tube defects in a population with high neural tube defect prevalence and no folic acid fortification. Pediatrics, 2009, 123:917-923. doi:10.1542/peds.2008-1173 pmid:19255021

14. Owen TJ, Halliday JL, Stone CA. Neural tube defects in Victoria, Australia: potential contributing factors and public health implications. Australian and New Zealand Journal of Public Health, 2000, 24:584-589. doi:10.1111/j.1467-842X.2000. tb00521.x pmid:11215005

15. Jentink J et al.; EUROCAT Antiepileptic Study Working Group. Valproic acid monotherapy in pregnancy and major congenital malformations. The New England Journal of Medicine, 2010, 362:2185-2193. doi:10.1056/NEJMoa0907328 pmid:20558369

16. Hernández-Díaz $S$ et al. Neural tube defects in relation to use of folic acid antagonists during pregnancy. American Journal of Epidemiology, 2001, 153:961-968. doi:10.1093/ aje/153.10.961 pmid:11384952

17. Shaw GM et al. Maternal height and prepregnancy body mass index as risk factors for selected congenital anomalies. Paediatric and Perinatal Epidemiology, 2000, 14:234-239. doi:10.1046/ j.1365-3016.2000.00274.x pmid:10949215

18. Shaw GM, Carmichael SL. Prepregnant obesity and risks of selected birth defects in offspring. Epidemiology (Cambridge, Mass.), 2008, 19:616-620. doi:10.1097/EDE.0b013e3181761fa3 pmid: 18552593

19. Watkins ML et al. Maternal obesity and risk for birth defects. Pediatrics, 2003, 111:1152-1158. pmid:12728129

20. Ren A et al. Association of selected persistent organic pollutants in the placenta with the risk of neural tube defects. Proceedings of the National Academy of Sciences of the United States of America, 2011, 108:12770-12775. doi:10.1073/pnas.1105209108 pmid:21768370

21. Liao $Y$ et al. Spatial analysis of neural tube defects in a rural coal mining area. International Journal of Environmental Health Research, 2010, 20:439-450. doi:10.1080/09603123.2010.4 91854 pmid:21161805

22. Moretti ME et al. Maternal hyperthermia and the risk for neural tube defects in offspring: systematic review and meta-analysis. Epidemiology (Cambridge, Mass.), 2005, 16:216-219. doi:10.1097/01.ede.0000152903.55579.15 pmid: 15703536

23. Czeizel AE, Dudás I. Prevention of the first occurrence of neuraltube defects by periconceptional vitamin supplementation. The New England Journal of Medicine, 1992, 327:1832-1835. doi:10.1056/NEJM199212243272602 pmid:1307234 
24. MRC Vitamin Study Research Group. Prevention of neural tube defects: results of the Medical Research Council Vitamin Study. Lancet, 1991, 338:131-137. doi:10.1016/01406736(91)90133-A pmid:1677062

25. Chan $A C$ et al. Folate awareness and the prevalence of neural tube defects in South Australia, 1966-2007. The Medical Journal of Australia, 2008, 189:566-569. pmid:19012555

26. Knudsen VK et al. Low compliance with recommendations on folic acid use in relation to pregnancy: is there a need for fortification? Public Health Nutrition, 2004, 7:843-850. doi:10.1079/ PHN2004630 pmid:15482608

27. South Australian Perinatal Practice Guidelines Workgroup. Vitamin and mineral supplementation in pregnancy. Adelaide, Department of Health, 2011 (http://www.health.sa.gov.au/PPG/Default. aspx?tabid=169\&PagelD $=813$, accessed 10 July 2012).

28. Scheil W et al. Pregnancy outcome in South Australia 2010. Adelaide, South Australian Department of Health, Pregnancy Outcome Unit, 2012 (http://www.sahealth.sa.gov.au/wps/wcm/ connect/9cead9004bb189b7a998eb501ddc6524/Pregnan $\mathrm{cy}+$ Outcome +in + South + Australia +2010.pdf?MOD=AJPE RES\&CACHEID = 9cead9004bb189b7a998eb501ddc6524, accessed 10 July 2012).

29. Chan A et al. Pregnancy outcome in South Australia 2009. Adelaide, South Australian Department of Health, Pregnancy Outcome Unit, 2011 (http://www.sahealth.sa.gov.au/wps/ wcm/connect/349eb60047edf25c9d6a9df22c7c1033/ pregnancy +outcome + sa +2009 -operations-pou-20110815. pdf? $\mathrm{mod}=$ ajperes\&cacheid $=349$ eb60047edf25c9d6a9df22c 7c1033, 10 July 2012).

30. Harper P. Standard Australian Classification of Countries (SACC) Second edition. Australian Bureau of Statistics, 2008 (http://www.ausstats.abs.gov.au/Ausstats/subscriber.nsf/0/9A9C4 59F46EF3076CA25744B0015610A/\$File/12690_second\%20 edition.pdf, accessed 12 November 2012).

31. Williams S, Nitschke M, Tucker G, Bi P. Extreme heat arrangements in South Australia: an assessment of trigger temperatures. Health Promotion Journal of Australia, 2011, 22 Spec No:S21-27.
32. Climate data online. Canberra, Australian Government, Bureau of Meteorology, 2012 (http://www.bom.gov.au/climate/data/index. shtml, accessed 20 May 2012).

33. Timmermans $S$ et al. Determinants of folic acid use in early pregnancy in a multi-ethnic urban population in The Netherlands: the Generation R study. Preventive Medicine, 2008, 47:427-432. doi:10.1016/j.ypmed.2008.06.014 pmid:18644404

34. Baraka MA et al. Determinants of folic acid use in a multi-ethnic population of pregnant women: a cross-sectional study. Journal of Perinatal Medicine, 2011, 39:685-692. doi:10.1515/ JPM.2011.085 pmid:21801033

35. Population Research and Outcome Studies Unit. The South Australian Monitoring and Surveillance System (SAMSS). Folate Awareness in South Australia, 2003-2011. Adelaide, South Australian Department of Health, 2011 (Unpublished report).

36. Dror DK, Allen LH. Interventions with vitamins B6, B12 and C in pregnancy. Paediatric and Perinatal Epidemiology, 2012, 26 Suppl 1:55-74. doi:10.1111/j.1365-3016.2012.01277.x pmid:22742602

37. McLean E, de Benoist B, Allen LH. Review of the magnitude of folate and vitamin B12 deficiencies worldwide. Food and Nutrition Bulletin, 2008, 29 Suppl:S38-51. pmid:18709880

38. Wang YA et al. Assisted reproductive technology in Australia and New Zealand. Assisted reproduction series number 15. Cat. No. PER 51. Canberra, Australian Institute of Health and Welfare, 2011 (http://www.aihw.gov.au/publication-detail/?id= 10737420465\&tab=2, accessed 12 June 2012).

39. Li Z et al. Australia's mothers and babies 2009. Perinatal statistics series no. 25. Cat. No. PER 52. Canberra, Australian Institute of Health and Welfare, 2011 (http://www.aihw.gov.au/publicationdetail/?id=10737420870, 22 June 2012).

40. Davies MJ et al. Reproductive technologies and the risk of birth defects. The New England Journal of Medicine, 2012, 366:18031813. doi:10.1056/NEJMoa1008095 pmid:22559061 